\title{
Genscheren-Forschung an der menschlichen Keimbahn: Plädoyer für eine neue Debatte auch in Deutschland
}

\author{
Bettina Schöne-Seifert
}

Online publiziert: 8. Mai 2017

(C) Springer-Verlag Berlin Heidelberg 2017

Am 1. März 2017 erschien die online-Veröffentlichung einer chinesischen Arbeitsgruppe, die erstmals an entwicklungsfähigen (aber nach dem Experiment verworfenen) Einzell-Embryonen experimentell mit Hilfe von CRISPR/Cas9-,,Genscheren“ (genome editing) zwei unterschiedliche krankmachende Punktmutationen zu korrigieren versucht hatte (Tang et al. 2017). Die Effizienz und Präzision dieses Eingriffs waren unerwartet hoch - wobei selbst den größten Optimisten klar ist, dass vor einem möglichen klinischen Einsatz noch enorm viel erfolgreiche Forschung erforderlich wäre, um berechtigte Risikosorgen auszuräumen. Immerhin aber rücken therapeutische Eingriffe an der menschlichen Keimbahn nun doch mit großer Geschwindigkeit in den Bereich des absehbar Machbaren. Diese Tatsache verdankt sich der Entdeckung und Weiterentwicklung besagter Genscheren in den letzten drei Jahren, aber ganz wesentlich auch den Erkenntnissen und Techniken der deskriptiven und funktionalen Genomik-Forschung der letzten drei Jahrzehnte, deren nicht selten in Abrede gestellte - medizinische Bedeutung nun doch zum Tragen zu kommen scheint. Allgemein begrüßt werden die Aussichten auf endlich erfolgreiche somatische Gentherapien mithilfe der neuen Reparaturtechnik, bei denen spezifische durch einzelne oder auch mehrere Gen-Defekte verursachte Erkrankungen (Muskelschwäche, Speicherkrankheiten u. a.) auf der Ebene der zuständigen Zellen behandelt würden. Bei aller Gefahr voreiliger Versprechungen und bedenklicher Heilversuche, denen dringend zu begegnen ist, zeichnen sich hier offenbar mittelfristig Behand-

Prof. Dr. B. Schöne-Seifert $(\bowtie)$

Institut für Ethik, Geschichte und Theorie der Medizin, Universität Münster,

Von-Esmarch-Str. 62, 48149 Münster, Deutschland

E-Mail: schoeneb@ukmuenster.de 
lungspotentiale für verschiedene schwere, zum Teil tödliche Krankheiten ab ${ }^{1}$ (Jarrett et al. 2017).

Keineswegs einstimmig werden hingegen die Aussichten auf therapeutische Keimbahneingriffe begrüßt. Die hiergegen und somit auch gegen entsprechende Forschung geltend gemachten ethischen Vorbehalte liegen auf verschiedenen Ebenen und sind grundsätzlich allesamt bekannt aus der ersten solchen Debattenrunde der 1980er- und 1990er-Jahre (z. B. Bayertz 1987; Enquete-Kommission 1987, Kap. 6.3.3.; Kitcher 1998). Damals hatte das umstrittene Projekt der HumangenomSequenzierung die Möglichkeiten späterer „Keimbahnmanipulationen“ immerhin in den Bereich des Denkbaren gerückt, bevor sie schließlich wieder als deutlich utopischer (oder dystopischer) galten, als der Anfangshype hatte glauben machen. Doch wenngleich es gewiss lohnt, einige der damals verfassten Abhandlungen und Streitschriften wieder zur Hand und zur Hilfe zu nehmen, scheinen auch neue Blicke auf die alten Argumente angebracht. Einige dieser Argumente sind zu abwegig, um näher betrachtet werden zu müssen - so die Thesen, jeder Eingriff in die menschliche Keimbahn sei bereits als solcher eine Verletzung der Menschenwürde, ein Akt der Blasphemie oder eine Form unzulässiger „Menschenzüchtung“. Hier wird einem genetischen Exzeptionalismus das Wort geredet, der schlechterdings nicht in Einklang mit dem systembiologischen Wissen um die Verfasstheit des Menschen gebracht werden kann: Ob eine Behandlung auf der Ebene der Gene, der Proteine oder der phänotypischen Symptome ansetzt, kann für sich allein genommen ersichtlich keine unterschiedliche normative Dignität haben. Abstrus ist auch das Argument, Keimbahntherapien an Gameten oder Embryonen seien bereits deswegen kategorisch unzulässig, weil die von diesen Eingriffen später Betroffenen selber ja nicht einwilligen könnten. Hier wird die Forderung nach persönlicher Einwilligung absurd überdehnt, die in analogen Kontexten der nicht-genetischen prä- oder postnatalen Therapie selbstverständlich zugunsten der am Kindeswohl orientierten elterlichen Einwilligung ausgesetzt wird.

Als Ausgangsthese vernünftig erscheint es daher, therapeutische Keimbahneingriffe nach Maßgabe ihres klinischen Nutzens an sich als ebenso wünschenswert zu bewerten wie jede andere wirksame medizinische Behandlung und davon erst im Lichte möglicher gravierender Gegengründe abzuweichen. Diese eigentlich selbstverständliche Ausgangsposition nehmen verschiedene aktuelle Gen-EditierungsStellungnahmen ein, zuletzt etwa diejenige des Nuffield-Councils oder der drei Nationalen US-Akademien (Nuffield Council on Bioethics 2016; National Academies 2017). Was nun sind oder wären solche Gegengründe?

Als erstes sind da die möglichen Risiken zu nennen - in ihrer Bedeutung potenziert durch ihre Weitergabe an nachfolgende Generationen. Während bis vor kurzem die Befürchtung im Vordergrund stand, Gene nicht punktgenau reparieren zu können oder durch die Träger der verwendeten Reparatursonden unerwünschte Nebeneffekte auszulösen, sind diese Sorgen mit den der Natur ,,abgeguckten“ neuen Präzisionsinstrumenten wohl zu Recht erheblich kleiner geworden. Auf der anderen Seite steigt in der scientific community offenbar das Bewusstsein für die Gefahr, dass mit der

\footnotetext{
${ }^{1}$ Sangamo Therapeutics, Inc. Product Pipeline. http://www.sangamo.com/product-pipeline (zugegriffen: 31. März 2017).
} 
Reparatur einer Punktmutation deren mögliche, aber noch unbekannte protektive Effekte verlorengehen oder unerwünschte epigenetische Effekte einhergehen könnten. Es wird in künftigen Debatten nicht zuletzt darauf ankommen, realistische und vorsichtige Risikobewertungen von der verbreiteten latenten Intuition zu unterscheiden, Naturbelassenes habe gewissermaßen ein normatives Prä.

Ein zweiter gegenwärtig prominenter Einwand behauptet die Entbehrlichkeit von Keimbahntherapien durch die Alternative der Präimplantationsdiagnostik (PID). Statt einen Embryo mit Genmutation im Kontext einer extrakorporalen Befruchtung genetisch zu verändern, lasse sich im Rahmen der extrakorporalen Befruchtung doch alternativ ein nicht-betroffener Embryo auswählen. Außer für seltene Konstellationen, in denen keine oder fast keine nicht-betroffenen Embryonen erzeugt werden können (z. B. wenn Eltern für die Mutation homozygot sind), trifft diese These für die große Mehrheit denkbarer monogener Genreparatur-Indikationen wohl in der Tat zu. Allerdings birgt die PID-Alternative zwar kein Risiko möglicher unerwarteter epigenetischer Effekte, würde aber ggf. sehr viel langsamer zur Eradizierung der krankmachenden Mutationen führen, wäre keine Option für polygene Korrekturen und erfordert zudem iteriert die Selektion (und Vernichtung) von Embryonen. Gerade dieser letzte Aspekt hat dazu geführt, dass Deutschland eine der einschränkendsten PID-Regelungen der westlichen Welt hat (vgl. Geffroy und Zerres 2016). Hier wird man also erneut auch über die Ethik des Embryonenschutzes diskutieren müssen.

Um eben diesen geht es, drittens, auch im Zusammenhang mit der Zulässigkeit von Genscheren-Forschung an menschlichen Keimbahnzellen. Deutschlands extrem restriktives Embryonenschutzgesetz von 1990 verbietet jede Form der Forschung an entwicklungsfähigen Embryonen - auch im frühesten Stadium. Hochrangige Erkenntnisgewinne über die menschliche Embryonalentwicklung, über gesunde und gestörte Genfunktionen sowie über deren medizinische Beeinflussungsmöglichkeit zu erzielen, bleibt damit ausländischen Forschern vorbehalten, mit denen deutsche Wissenschaftler auch nicht kooperieren dürfen. Das alles wäre offenkundig ein unbedingt zu zahlender „Preis“, wenn die hinter dem Embryonenschutzgesetz stehende Position des vollen Würde- und Lebensschutzes bereits für befruchtete menschliche Eizellen ihrerseits einleuchtend begründbar wäre. Doch wird sie in einer säkularisierten und biologisch informierten Gesellschaft wohl eher zunehmend strittig und ist nach Ansicht mancher daher politisch erneut zur Diskussion zu stellen (Bonas et al. 2017). Die u. U. provozierende Diagnose, das Embryonenschutzgesetz sei nicht mehr ,zeitgemäß“, muss also keineswegs ein „Einknicken“ der Ethik vor den Interessen von Forschern oder künftigen Patienten zum Ausdruck bringen, sondern vielmehr die fragliche Überzeugungskraft einer ethischen Prämisse, die in neuem Licht zu diskutieren wäre.

Viertens und fünftens schließlich wird gegen die Option einer zukünftigen Keimbahntherapie ins Feld geführt, es würden sich keine haltbaren Bollwerke gegen die genetische Behandlung immer trivialerer Krankheiten oder auch bloßer Krankheitsrisiken errichten lassen - und am Ende auch keine gegen die genetische Optimierung von Nachkommen - jenseits von Krankheitsbekämpfung. Ob das einleuchtet, was daran ggf. im Einzelnen problematisch wäre und was nicht - und ob diese Befürchtungen wirklich ein hinreichender Grund für ein ethisches Verbot der Keimbahnthe- 
rapie und der ihr möglicherweise den Weg ebnenden Forschung wäre - all das sollte informiert und offen diskutiert werden. Es steht, so oder so, viel auf dem Spiel: zu viel, um an eingefahrenen Positionen einfach festzuhalten.

Einen daher besonders willkommenen Beitrag leisten schon im nächsten Heft dieser Zeitschrift ein Pro- und ein Contra-Plädoyer für Forschung im Dienste menschlicher Keimbahntherapie, die vorab bereits online gelesen werden können (Kipke et al. 2017; Rütsche 2017).

\section{Literatur}

Bayertz K (1987) GenEthik: Probleme der Technisierung menschlicher Fortpflanzung. Rowohlt TB, Reinbek

Bonas U, Friedrich B, Fritsch J et al (2017) Ethische und rechtliche Beurteilung des genome editing in der Forschung an humanen Zellen. Diskussionspapier der Nationalakademie Leopoldina. Druckhaus Köthen, Köthen

Enquete-Kommission Chancen und Risiken der Gentechnologie (1987) Bericht Chancen und Risiken der Gentechnologie. Enquete-Kommission des Deutschen Bundestages. dip21.bundestag.de/dip21/btd/ 10/067/1006775.pdf. Zugegriffen: 31. März 2017

Geffroy S, Zerres K (2016) Präimplantationsdiagnostik im Europavergleich. Med Genet 28(3):320-325

Jarrett KE, Lee CM, Yeh Y-H et al (2017) Somatic genome editing with CRISPR/Cas9 generates and corrects a metabolic disease. Sci Rep 7:44624

Kipke R, Rothhaar M, Hähnel M (2017) Contra: Soll das sogenannte „Gene Editing“ mittels CRISPR/Cas9-Technologie an menschlichen Embryonen erforscht werden? Ethik Med. doi:10.1007/ s00481-017-0435-y

Kitcher P (1998) Genetik und Ethik: die Revolution der Humangenetik und ihre Folgen. Luchterhand, München

National Academies of Sciences, Engineering, and Medicine (2017) Human genome editing: science, ethics, and governance. Prepublication. National Academy Press, Washington DC

Nuffield Council on Bioethics (2016) Genome editing: an ethical review. http://nuffieldbioethics.org/wpcontent/uploads/Genome-editing-an-ethical-review.pdf. Zugegriffen: 31. März 2017

Rütsche B (2017) Pro: Soll das sogenannte „Gene Editing“ mittels CRISPR/Cas9-Technologie an menschlichen Embryonen erforscht werden? Ethik Med. doi:10.1007/s00481-017-0436-X

Tang L, Zeng Y, Du H et al (2017) CRISPR/Cas9-mediated gene editing in human zygotes using Cas9 protein. Mol Genet Genomics. doi:10.1007/s00438-017-1299-z 